\title{
Signaling pathway inhibitors target breast cancer stem cells in triple-negative breast cancer
}

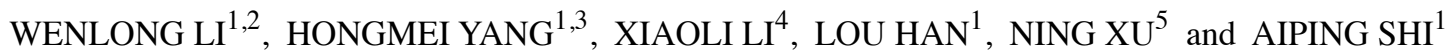 \\ ${ }^{1}$ Department of Breast Surgery, The First Bethune Hospital of Jilin University, Changchun, Jilin 130021; \\ ${ }^{2}$ Department of Breast and Thyroid, Dongying People's Hospital, Dongying, Shangdong 257091; \\ ${ }^{3}$ Department of Anesthesia, The Fourth Hospital of Jilin University, Changchun, Jilin 130021; \\ ${ }^{4}$ Department of Pathology, Beihua University, Jilin, Jilin 132013; ${ }^{5}$ Department of Urology, \\ The First Bethune Hospital of Jilin University, Changchun, Jilin 130021, P.R. China
}

Received May 4, 2018; Accepted October 11, 2018

DOI: 10.3892/or.2018.6805

\begin{abstract}
The present study aimed to investigate the efficacy of five signaling pathway inhibitors, $N$-[N-(3,5-difluorophenacetyl)L-alanyl]-S-phenylglycine $t$-butyl ester, vismodegib, salinomycin, ruxolitinib and stattic, as novel therapeutic agents that target breast cancer stem cells (BCSCs) in triple-negative breast cancer (TNBC). The in vitro anti-proliferative, anti-invasive, pro-apoptotic and inhibitory effects on BCSC self-renewal of these signaling pathway inhibitors on the TNBC stem cell line HCC38 were examined by MTT assays, Matrigel invasion assays, flow cytometry and suspension mammosphere assays, respectively. For the in vivo study, another TNBC stem cell line, HCC1806, pretreated with these signaling pathway inhibitors, was inoculated into female nonobese diabetic/severe combined immunodeficient mice, and the tumor volumes were measured following tumor formation. Treatment of HCC38 cells with each signaling pathway inhibitor significantly decreased TNBC cell proliferation, cell invasion and mammosphere formation
\end{abstract}

Correspondence to: Dr Aiping Shi, Department of Breast Surgery, The First Bethune Hospital of Jilin University, 71 Xinmin Street, Changchun, Jilin 130021, P.R. China

E-mail: 13364308696@163.com

Abbreviations: ALDH1, aldehyde dehydrogenase 1; BCSCs, breast cancer stem cells; bFGF, basic fibroblast growth factor; cl-Notch1, cleaved Notch1 intracellular domain; DAPT, $N-[N-(3,5-$ difluorophenacetyl)-L-alanyl]- $S$-phenylglycine $t$-butyl ester; DMSO, dimethyl sulfoxide; EGF, epidermal growth factor; FBS, fetal bovine serum; GDC-0449, vismodegib; HER2, human epidermal growth factor receptor 2; JAK, Janus kinase; NOD/SCID, non-obese diabetic/severe combined immunodeficient; PTCH, Patched; SMO, smoothened; STAT3, signal transducer and activator of transcription 3; TBST, Tris-buffered saline containing Tween-20; TNBC, triple-negative breast cancer; Wnt, wingless-type MMTV integration site family

Key words: TNBC, BCSCs, signaling pathway inhibitors, ALDH1, Notch, Hedgehog, JAK while inducing cell apoptosis by inhibiting the protein expression or phosphorylation of downstream signaling molecules. In the xenograft mouse models, tumor formation and growth of HCC 1806 cells pretreated with each signaling pathway inhibitor were effectively suppressed. Treatment with these signaling pathway inhibitors may provide a novel therapeutic strategy against TNBC by targeting BCSCs, thus providing promising insight for clinical applications in patients with TNBC.

\section{Introduction}

Breast cancer is the most frequently diagnosed cancer and the leading cause of cancer-associated mortality in women worldwide (1). It accounts for $30 \%$ all novel cancer diagnoses in women (1). Triple-negative breast cancer (TNBC), characterized by the absence of estrogen receptor and progesterone receptor in addition to a lack of overexpression of human epidermal growth factor receptor 2 (HER2), accounts for $15 \%$ breast cancer cases $(2,3)$. As a distinct subtype of breast cancer, TNBC does not respond to the standard endocrine therapies, including tamoxifen (an anti-estrogen agent against the estrogen receptor) and trastuzumab (a monoclonal antibody against HER2), thus presenting a clinical challenge, as it is associated with a higher incidence of visceral metastases, poorer prognosis, shorter survival and higher risk of distant recurrence compered with other types of breast cancer (2). Identifying novel potential targets and novel therapeutic options are urgently required to manage this aggressive type of breast cancer.

Increasing evidence suggested that the aggressiveness of TNBC and its resistance to standard drug therapies may be partially due to the presence of breast cancer stem cells (BCSCs) within TNBC tumors in addition to the normal tissue adjacent to TNBC tumors (4-6). In human cancer, including breast cancer, there is a small population of cancer stem cells, which are capable of self-renewal, differentiation, and tumor initiation and development (7). In breast cancer, a subpopulation of breast cancer cells [CD44 antigen $\left(C D 44^{+}\right) /$signal transducer (CD24) CD24-/low $]$ was isolated and defined as BCSCs, which have unique stem cell-like properties that may contribute to chemotherapy and/or radiotherapy resistance (8). 
In addition to the expression of CD44 and CD24, an alternate cell surface marker, aldehyde dehydrogenase 1 (ALDH1), has been used to identify BCSCs (8-11). Ginestier et al (11) identified that only $\mathrm{ALDH}^{+}$cells may develop tumors in mice, albeit in small numbers, whereas $\mathrm{CD} 44^{+} / \mathrm{CD} 24^{-}$is not able to. ALDH1 is additionally considered a predictor of prognosis in patients with breast cancer (12-15). Therefore, ALDH1 was used as a BCSC marker in the present study.

In BCSCs, the stem-like properties, including self-renewal, treatment-resistance and aggressiveness, are coordinated by a network of cellular signaling pathways, including the Notch, Hedgehog, wingless-type MMTV integration site family (Wnt)/ $\beta$-catenin, and Janus kinase (JAK)/signal transducer and activator of transcription 3 (STAT3) signaling pathways (16). Aberrations in one or more of these signaling pathways have been identified in cancer stem cells, including BCSCs (16). Therefore, targeting these signaling pathways in BCSCs is an attractive strategy for TNBC therapy (17).

In the present study, using triple-negative, $\mathrm{ALDH} 1^{+} \mathrm{BCSC}$ lines HCC38 and HCC1806, in vitro and in vivo studies were conducted to investigate the anti-tumor effects of five signaling pathway inhibitors, $N$-[N-(3,5-difluorophenacetyl)-L-alanyl]$S$-phenylglycine $t$-butyl ester (DAPT; Notch pathway inhibitor), vismodegib (GDC-0449; Hedgehog pathway inhibitor), salinomycin (Wnt/ $\beta$-catenin pathway inhibitor), ruxolitinib and stattic (JAK/STAT3 pathway inhibitors; Table I), on BCSCs in TNBC.

\section{Materials and methods}

Reagents and cell culture. DAPT, salinomycin, MTT, hydrocortisone and insulin were purchased from Sigma-Aldrich (Merck KGaA, Darmstadt, Germany). GDC-0449, ruxolitinib and stattic were obtained from Selleck Chemicals (Houston, TX, USA). RPMI-1640, B27, penicillin and streptomycin were obtained from Gibco (Thermo Fisher Scientific, Inc., Waltham, MA, USA). Epidermal growth factor (EGF) and basic fibroblast growth factor (bFGF) were provided by Prospec-Tany TechnoGene, Ltd. (East Brunswick, NJ, USA). The HCC38 breast cancer cell line was obtained from The American Type Culture Collection (Manassas, VA, USA). The HCC1806 breast cancer cell line was provided by Dr Shibo Fu at the Transform Medical College of The First Hospital of Jilin University (Changchun, China). The two cell lines were grown in RPMI 1640 supplemented with $10 \%$ fetal bovine serum (FBS; Gibco; Thermo Fisher Scientific, Inc.; cat. no. 16000-044), penicillin $(6.25 \mu \mathrm{g} / \mathrm{ml})$ and streptomycin $(100 \mu \mathrm{g} / \mathrm{ml})$ at $37^{\circ} \mathrm{C}$ in a humidified atmosphere of $5 \% \mathrm{CO}_{2}$. The two cell lines were tested and validated by the Department of Cell Biology, Institute of Basic Medical Science, Chinese Academy of Medical Science (Beijing, China) and the Cell Resource Center of the Shanghai Institute of Biological Science (Shanghai, China).

MTT cell proliferation assay. HCC 38 breast cancer cells were seeded in 96-well plates at a density of $2 \times 10^{3}$ cells/well in serum-free RPMI-1640. On the following day, cells were treated at $37^{\circ} \mathrm{C}$ with DAPT $(10,20$ and $40 \mu \mathrm{M})$, GDC-0449 $(10,20$ and $40 \mu \mathrm{M})$, salinomycin $(10,20$ and $40 \mu \mathrm{M})$ for $24 \mathrm{~h}$, or ruxolitinib $(1,10$ and $20 \mu \mathrm{M})$ and stattic $(1,10$ and $20 \mu \mathrm{M})$ for $72 \mathrm{~h}$. Dimethyl sulfoxide (DMSO) was used as a vehicle
Table I. Signaling pathways and inhibitors.

\begin{tabular}{lll}
\hline $\begin{array}{l}\text { Signaling pathway } \\
\text { inhibitors }\end{array}$ & \multicolumn{1}{c}{$\begin{array}{l}\text { Signaling } \\
\text { pathways }\end{array}$} & \multicolumn{1}{c}{ Targets } \\
\hline DAPT & Notch & $\gamma$-secretase \\
GDC-0449 & Hedgehog & SMO \\
Salinomycin & Wnt/ $\beta$-catenin & $\beta$-catenin \\
Ruxolitinib & JAK/STAT & JAK \\
Stattic & JAK/STAT & STAT3 \\
\hline
\end{tabular}

DAPT, $\quad N$-[N-(3,5-difluorophenacetyl)-L-alanyl]-S-phenylglycine $t$-butyl ester; SMO, smoothened; JAK, janus kinase; STAT, signal transducer and activator of transcription; GDC-0449, vismodegib.

control. MTT reagent was added and incubated for $1 \mathrm{~h}$ at $37^{\circ} \mathrm{C}$. The absorbance was measured at $570 \mathrm{~nm}$ using a SynergyHT microplate reader (BioTek Instruments, Inc., Winooski, VT, USA). Data were analyzed using Excel 12.0 (Microsoft Corporation, Redmond, WA, USA).

Apoptosis assay by flow cytometry. HCC38 cells were treated with vehicle or each signaling pathway inhibitor for the indicated time, and $1 \times 10^{6}$ cells were subsequently trypsinized to obtain a single-cell suspension. Apoptosis analysis was performed by flow cytometry using an Annexin V Apoptosis Detection kit (BD Biosciences, Franklin Lakes, NJ, USA), according to the manufacturer's protocol. Cells were stained with Annexin V-fluorescein isothiocyanate and propidium iodide on ice for $20 \mathrm{~min}$ prior to analysis. Data acquisition was performed on an LSR-II flow cytometer (BD Biosciences) with FACSDiva 8.0.1 software (BD Biosciences).

Mammosphere formation assay. For primary mammosphere culture, HCC38 cells were harvested from monolayer culture and resuspended by gentle aspiration to obtain a single-cell suspension. The cells were subsequently seeded at a density of $1 \times 10^{5}$ cells/well in ultra-low attachment 6-well plates (Costar; Corning, Inc., Corning, NY, USA), and grown in serum-free Dulbecco's modified Eagle's medium/F12 (Hyclone; GE Healthcare Life Sciences, Logan, UT, USA) supplemented with $2 \% \mathrm{~B} 27,20 \mathrm{ng} / \mathrm{ml}$ EGF, $20 \mathrm{ng} / \mathrm{ml} \mathrm{bFGF}, 6.25 \mu \mathrm{g} / \mathrm{ml}$ penicillin, $100 \mu \mathrm{g} / \mathrm{ml}$ streptomycin, $1 \mathrm{ng} / \mathrm{ml}$ hydrocortisone and $10 \mathrm{mg} / \mathrm{ml}$ insulin. Cells were divided into two groups; one group was pretreated with DMSO or signaling pathway inhibitors on the following day; and the other was treated immediately following mammosphere formation. After incubation for 7 or 14 days following the treatments, mammospheres $>50 \mu \mathrm{m}$ in diameter were counted and imaged under an inverted light microscope (Olympus IX51; Olympus Corporation, Tokyo, Japan; magnification, $\mathrm{x} 20$ ).

Matrigel invasion assay. A cell invasion assay was performed using 24-well BD biocoat Matrigel invasion chambers with an $8.0-\mu \mathrm{m}$ pore size (BD Biosciences) according to the manufacturer's protocol. In total, $4 \times 10^{4} \mathrm{HCC} 38$ cells were loaded into the Matrigel-coated upper chamber filled with $500 \mu 1$ serum-free RPMI containing DMSO or a signaling pathway 

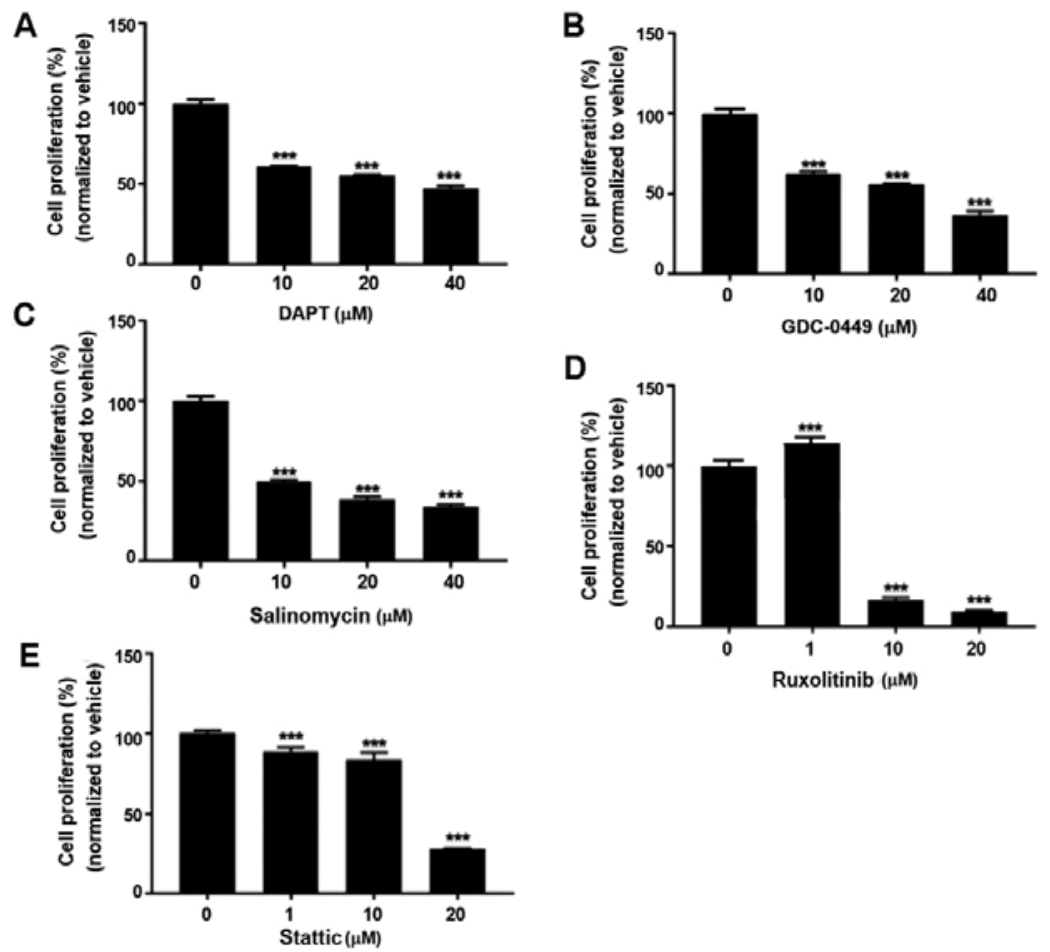

Figure 1. Anti-proliferative effects of the signaling pathway inhibitors on HCC38 cells. Cell proliferation was measured using an MTT assay following cell treatment with (A) DAPT, (B) GDC-0449, (C) salinomycin, (D) ruxolitinib and (E) stattic. Data are presented as the mean \pm standard deviation. $n=4 .{ }^{* * *} \mathrm{P}<0.001$ vs. respective $0 \mu \mathrm{M}$. DAPT, $N$-[ $N$-(3,5-difluorophenacetyl)-L-alanyl]- $S$-phenylglycine $t$-butyl ester; GDC-0449, vismodegib.

inhibitor. To induce cell invasion, 10\% FBS-containing RPMI was loaded into the lower chamber. Following incubation overnight, non-invading cells remaining in the upper chamber were removed with a cotton swab. The invading cells that were adhered to the lower surface were fixed for $20 \mathrm{~min}$ in $4 \%$ paraformaldehyde at $4^{\circ} \mathrm{C}$ and stained in $0.1 \%$ crystal violet solution at $25^{\circ} \mathrm{C}$ for 15 min using Diff-Quik (Siemens AG, Munich, Germany). The stained cells were counted in five randomly selected fields under an inverted light microscope (Olympus IX51; Olympus Corporation; magnification, x20).

Western blot analysis. HCC38 cells were treated with DMSO or different concentrations of signaling pathway inhibitors for $24 \mathrm{~h}$ and lysed with lysis buffer (Cell Signaling Technology, Danvers, MA, USA; cat. no. 9803) on ice. Cell lysates were collected by centrifugation at $13,800 \mathrm{x} \mathrm{g}$ at $4^{\circ} \mathrm{C}$ for $10 \mathrm{~min}$. The protein concentration was measured using a bicinchoninic acid protein assay kit with bovine serum albumin, according to the manufacturer's protocol (Beyotime Institute of Biotechnology, Haimen, China; cat. no. P0010). Subsequently, protein samples were heated at $95^{\circ} \mathrm{C}$ for $5 \mathrm{~min}$ in loading buffer. In total, $30 \mu \mathrm{g}$ protein was loaded in each lane and separated by $10 \%$ SDS-PAGE, transferred to a polyvinylidene difluoride membrane and blocked for $1 \mathrm{~h}$ with $5 \%$ non-fat milk in Tris-buffered saline containing Tween-20 (TBST) at room temperature. Subsequently, the membranes were incubated overnight with primary antibodies against cleaved Notch1 (cat. no. 4147; 1:1,000), zinc finger protein GLI1 (cat. no. 3538; 1:1,000), $\beta$-catenin (cat. no. 8480; 1:1,000; all Cell Signaling Technology, Inc.), STAT3 (cat. no. ab68153; 1:1,000), phosphoSTAT3 (cat. no. ab76315; 1:2,000), JAK1 (cat. no. ab133666; 1:1,000), JAK2 (cat. no. ab108596; 1:2,000) and $\beta$-actin (cat. no. ab8226; 1:1,000; all Abcam, Cambridge, UK) at $4^{\circ} \mathrm{C}$. The membranes were washed with TBST three times, subsequently incubated with horseradish peroxidase-conjugated secondary antibodies [cat. no. 7076, anti-mouse immunoglobulin G (IgG), 1:2,000; cat. no. 7074, anti-rabbit IgG, 1:2,000; both Cell Signaling Technology, Inc.] for $1 \mathrm{~h}$ at room temperature, and washed with TBST. An enhanced chemiluminescence kit (Thermo Fisher Scientific, Inc.; cat. no. 32106) was used and the signal was detected using the ChemiScope 5300 chemiluminescence system (Clinx Science Instruments Co. Ltd., Shanghai, China) and quantified using Quantity One software (v4.6.6; Bio-Rad Laboratories, Inc., Hercules, CA, USA).

Mouse xenograft and orthotopic tumor models. In total, 54 female nonobese diabetic/severe combined immunodeficient (NOD/SCID) mice (National Institute of Food and Drug Control of China, Beijing, China), 5-6 weeks old and weighing 15-20 g were bred and maintained under specific pathogenfree conditions (temperature at $18-29^{\circ} \mathrm{C}$; air changes $10-20 / \mathrm{h}$; air velocity $<0.18 \mathrm{~m} / \mathrm{sec} ; 12 \mathrm{~h}$ light/dark cycle; and free access to food and water) at The Animal Experiment Center, Basic Medical College of Jilin University (Changchun, China). All the animal care details and procedures described in the present study were approved by the Ethics Committee of The First Hospital of Jilin University. All animal experiments were performed in accordance with guidelines for proper conduct of animal experiments (Jilin University). The MTT assay determined that $10 \mu \mathrm{M}$ was the value close to the half maximal inhibitory concentration $\left(\mathrm{IC}_{50}\right)$ of the majority of the inhibitors in the present study. The cells were more sensitive to ruxolitinib compared with the other inhibitors; $3 \mu \mathrm{M}$ was the value close to the $\mathrm{IC}_{50}$ of ruxolitinib. Triple-negative and $\mathrm{ALDH} 1^{+}$ 

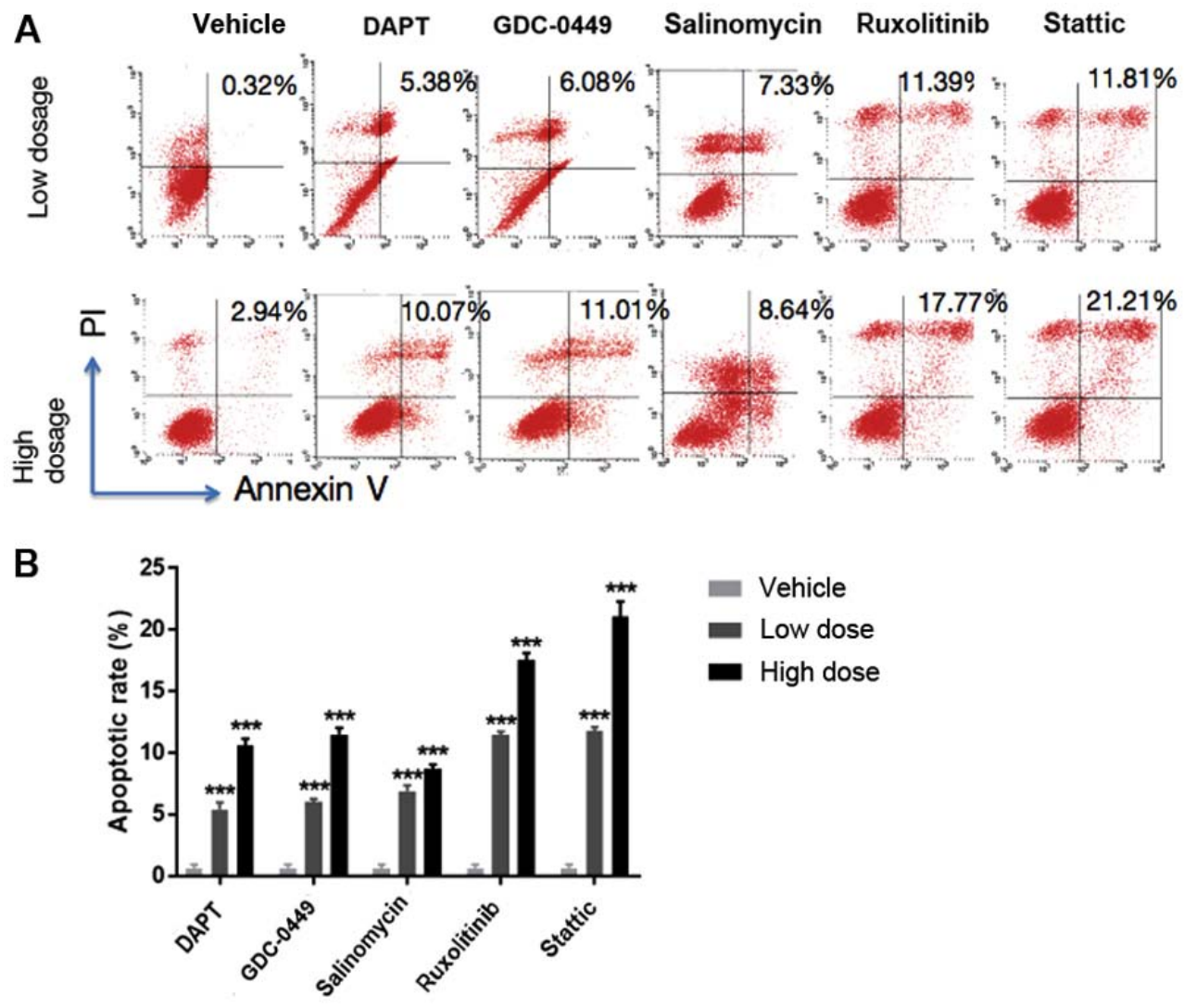

Figure 2. Pro-apoptotic effects of signaling pathway inhibitors on HCC38 cells. (A) Apoptotic rates of HCC38 cells treated with vehicle, DAPT, GDC-0449, salinomycin, ruxolitinib and stattic. (B) Quantification of the apoptotic rates. Data are presented as the mean \pm standard deviation. All experiments were repeated at least three times. $\mathrm{n}=3 .{ }^{* * *} \mathrm{P}<0.001$ vs. respective vehicle. DAPT, $N$-[N-(3,5-difluorophenacetyl)-L-alanyl]-S-phenylglycine $t$-butyl ester; GDC-0449, vismodegib; PI, propidium iodide.

HCC1806 cells were pretreated in vitro with DMSO, DAPT $(10 \mu \mathrm{M})$, GDC-0449 $(10 \mu \mathrm{M})$, salinomycin $(10 \mu \mathrm{M})$, ruxolitinib $(3 \mu \mathrm{M})$ or stattic $(10 \mu \mathrm{M})$ for $4 \mathrm{~h}$ prior to mixing with an equal volume of Matrigel (BD Biosciences). The mice were randomly divided into six groups ( $\mathrm{n}=9 /$ group) and injected with a mixture of pretreated HCC1806 cells and Matrigel into the mammary fat pad, as previously described (18). Following the initial appearance, tumors were measured every 2 days using a caliper. Tumor volumes were calculated using the formula (length $\mathrm{x}$ width $\left.{ }^{2}\right) / 2$ (19). The tumor-free survival rate of mice was analyzed using the Kaplan-Meier method and the $\log$ rank test.

Statistical analysis. All experiments were repeated at least three times. Data are presented as the mean \pm standard deviation. Statistical significance was assessed using Student's t-test or one-way analysis of variance to compare multiple groups followed by Tukey's or Welch's t-test (variances are not equal) to conduct multiple comparisons between the groups with SPSS 16.0 statistical software (SPSS Inc., Chicago, IL, USA). $\mathrm{P}<0.05$ was considered to indicate a statistically significant difference.

\section{Results}

Signaling pathway inhibitors suppress BCSC proliferation. To determine if various signaling pathway inhibitors have effects on BCSC proliferation, an MTT assay was conducted on HCC 38 cells. As presented in Fig. 1, the inhibitors generally suppressed the proliferation of HCC 38 cells in a dose-dependent manner, suggesting the anti-proliferative roles of these inhibitors in BCSCs.

Signaling pathway inhibitors induce apoptosis of BCSCs. To further investigate if the five signaling pathway inhibitors induce BCSC apoptosis, which is another important cellular event in breast cancer therapy in addition to cell proliferation, a flow cytometry assay was performed in HCC 38 cells. As presented in Fig. 2, treatment with DAPT, GDC-0449, salinomycin, ruxolitinib and stattic resulted in a significantly increased apoptotic percentage $\leq 10.07,11.01,8.64,17.77$ and $21.21 \%$, respectively, compared with the vehicle-treated cells $(\mathrm{P}<0.001)$, suggesting the pro-apoptotic roles of these inhibitors in BCSCs.

Signaling pathway inhibitors suppress invasion of BCSCs. Cell invasion is a key process in cancer metastasis (20). To investigate the potential effects of the signaling pathway inhibitors on the capacity of BCSC invasion, invasion assays were performed. As presented in Fig. 3, a significantly lower number of invading HCC38 cells was observed with treatment with DAPT, GDC-0449, salinomycin, ruxolitinib and stattic, compared with the vehicle-treated group $(\mathrm{P}<0.001)$, suggesting that the signaling pathway inhibitor-mediated suppression of BCSC invasion is a possible mechanism in metastatic breast cancer therapy. 

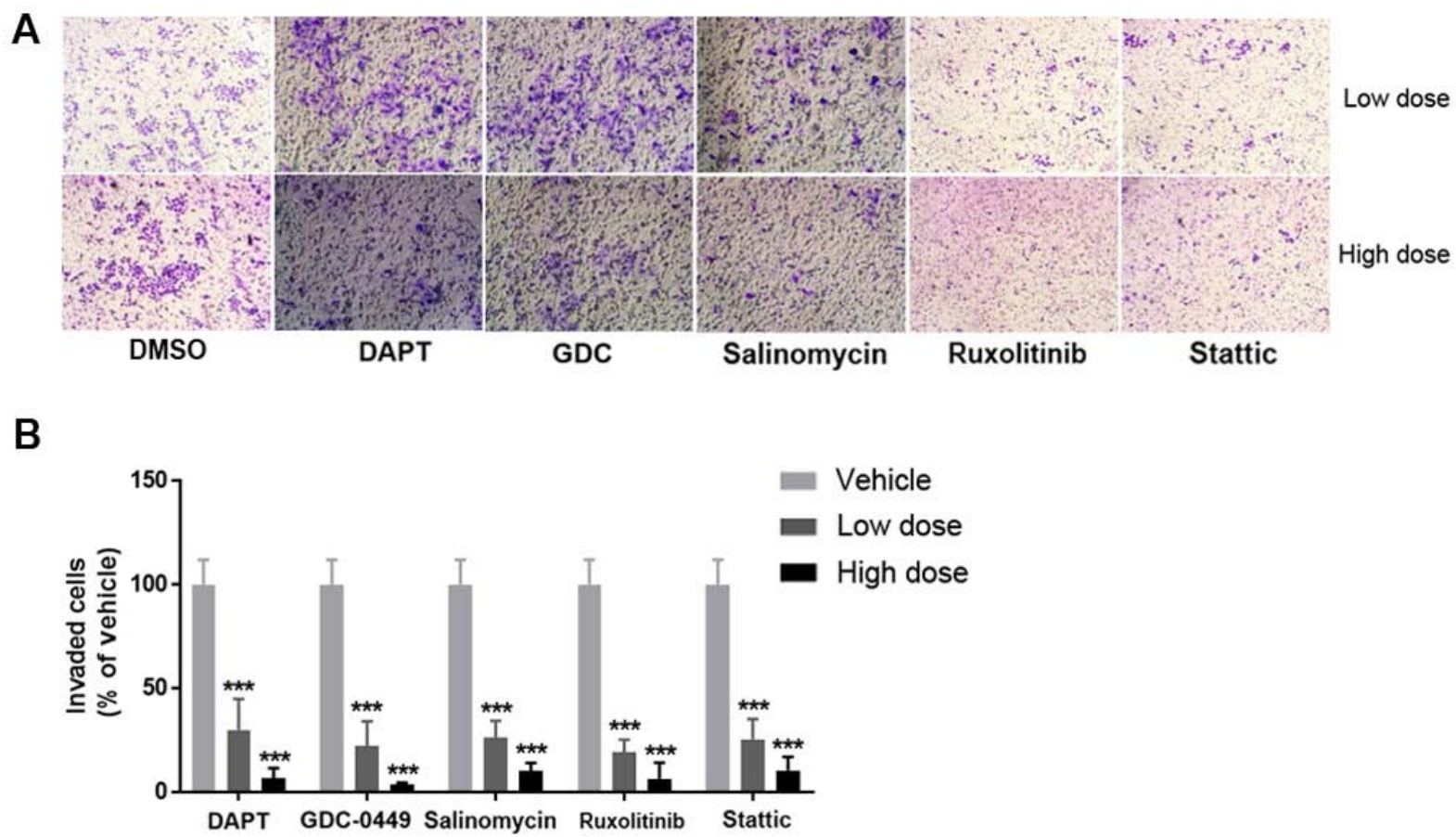

Figure 3. Signaling pathway inhibitors suppress invasion of HCC38 cells. (A) Representative images of invading cells in the Transwell assay are presented. Magnification, x20. (B) Quantification of the number of invaded cells. All experiments were repeated at least three times. $\mathrm{n}=6$. Data are presented as the mean \pm standard deviation. ${ }^{* * *} \mathrm{P}<0.001$ vs. respective vehicle. DMSO, dimethyl sulfoxide; DAPT, $N$-[ $N$-(3,5-difluorophenacetyl)-L-alanyl]-S-phenylglycine $t$-butyl ester; GDC, GDC-0449/vismodegib.
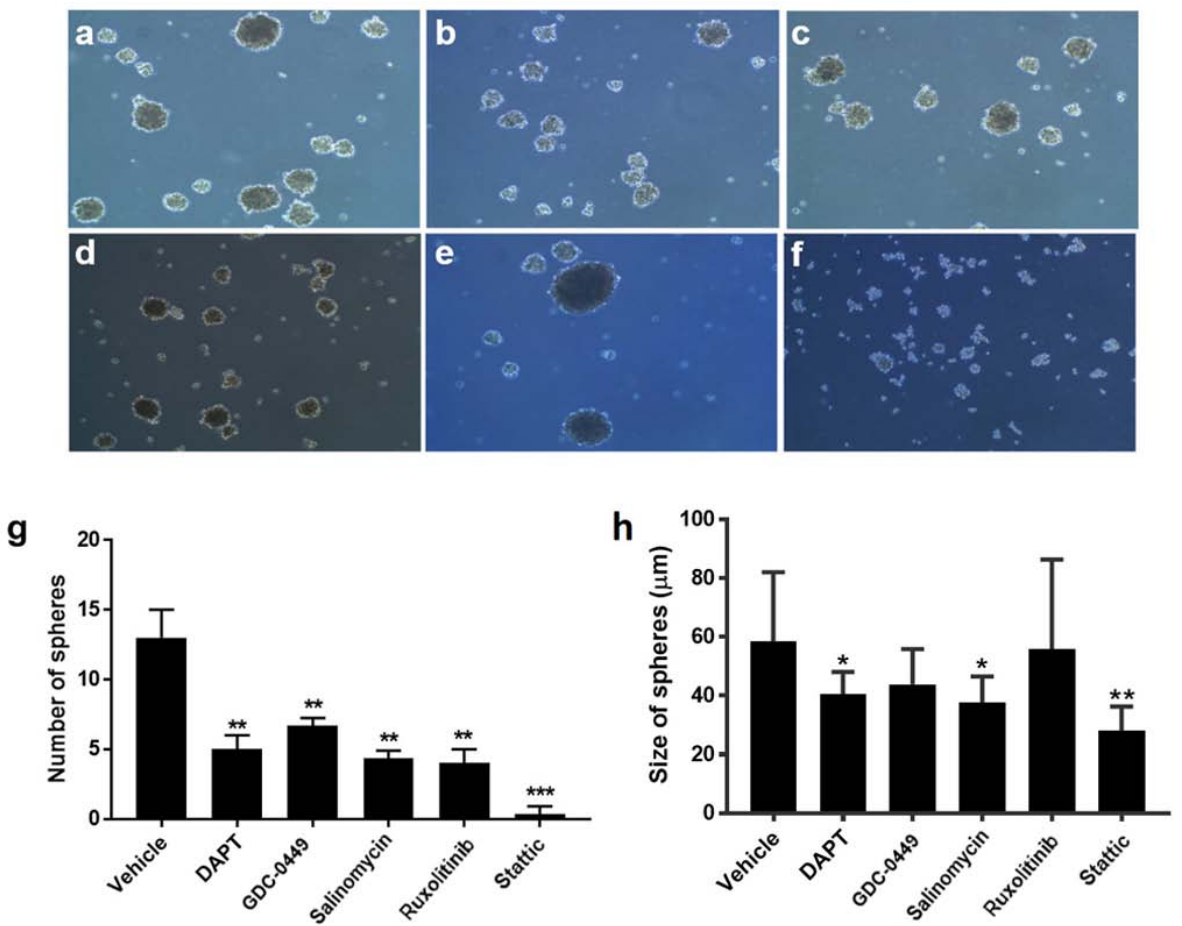

Figure 4. Signaling pathway inhibitors suppress mammosphere formation of HCC38 cells. Morphology of HCC38 cell-formed mammospheres after a 7-day pretreatment with (a) vehicle, (b) $20 \mu \mathrm{M}$ DAPT, (c) $20 \mu \mathrm{M}$ GDC-0449, (d) $40 \mu \mathrm{M}$ salinomycin, (e) $10 \mu \mathrm{M}$ ruxolitinib or (f) $5 \mu \mathrm{M}$ stattic under a microscope. Magnification, x20. (g) Quantification of the number of mammospheres formed after a 7-day incubation with the inhibitors. (h) Quantification of the size of mammospheres formed after a 7-day incubation with the inhibitors. All experiments were repeated at least three times. $\mathrm{n}=3 .{ }^{*} \mathrm{P}<0.05,{ }^{* * *} \mathrm{P}<0.01,{ }^{* * *} \mathrm{P}<0.001 \mathrm{vs}$. vehicle. DAPT, $N$-[N-(3,5-difluorophenacetyl)-L-alanyl]-S-phenylglycine $t$-butyl ester; GDC-0449, vismodegib.

Signaling pathway inhibitors suppress BCSC self-renewal. As stem cell self-renewal serves a critical role in stem cell proliferation and differentiation, which are closely associated with cancer development $(21,22)$, it was investigated whether the five inhibitors affect BCSC self-renewal. A suspension mammosphere assay, which is commonly used for measuring 


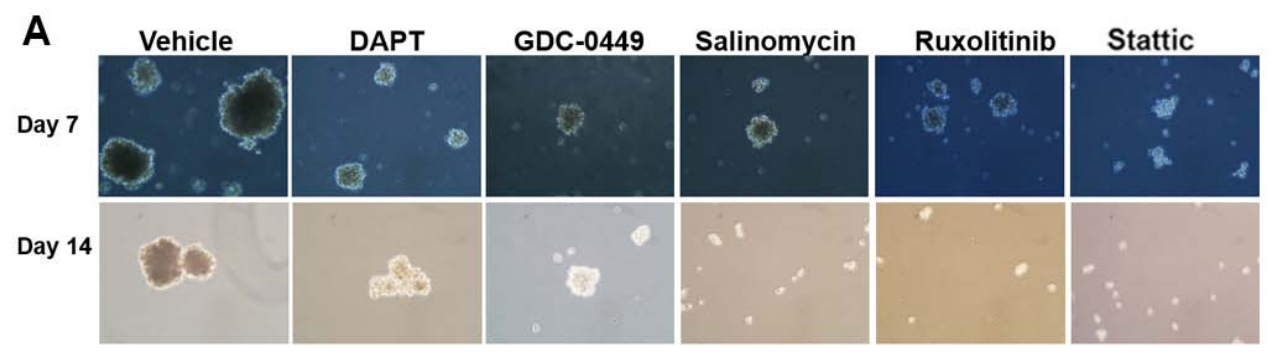

B

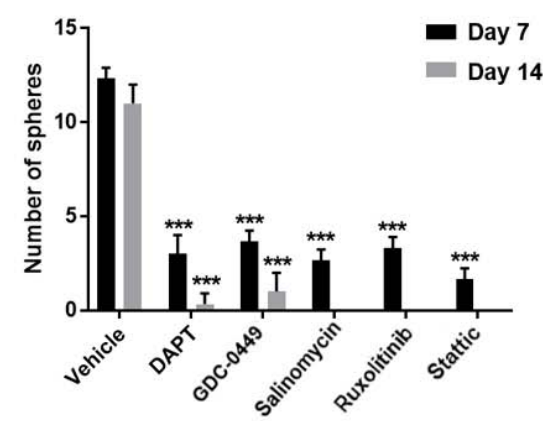

Figure 5. Signaling pathway inhibitors promote the disassembly of HCC38 cell-formed mammospheres. (A) Morphology of HCC38-formed mammospheres treated with signaling pathway inhibitors immediately following mammosphere formation. Magnification, $\mathrm{x} 20$. (B) Quantification of the number of mammospheres formed after 7-day and 14-day incubations following the treatments. All experiments were repeated at least three times. $\mathrm{n}=3$. ${ }^{* * *} \mathrm{P}<0.001$ vs. respective vehicle. DAPT, $N$-[ $N$-(3,5-difluorophenacetyl)-L-alanyl]- $S$-phenylglycine $t$-butyl ester; GDC-0449, vismodegib.

stem cell activity and in vitro stem/progenitor cell frequency, was performed on HCC 38 cells. The results demonstrated that pretreatment with signaling pathway inhibitors prior to mammosphere formation markedly decreased the sphere size and the number of HCC38 cells, compared with the vehicletreated control (Fig. 4). Among the inhibitors, stattic was the most potent one, as demonstrated by the lack of any mammospheres (Fig. 4f-h).

Similarly, treatment with the signaling pathway inhibitors immediately following mammosphere formation failed to maintain the structure of the formed mammosheres (Fig. 5). Following prolonged incubation, treatment with salinomycin, ruxolitinib and stattic even led to further disassembly of mammospheres (Fig. 5). These results demonstrated that the signaling pathway inhibitors diminished the tumorsphere-forming ability of BCSCs and the maintenance of BCSC-formed mammospheres, suggesting the negative roles of these inhibitors in the BCSC self-renewal process.

Signaling pathway inhibitors suppress expression and phosphorylation of downstream targets. As the inhibitors block signal transduction, they were predicted to inhibit the activity of their downstream target molecules. In general, these inhibitors markedly decreased the expression or phosphorylation of their corresponding downstream signaling molecules in a dose-dependent manner, as demonstrated in Fig. 6.

Signaling pathway inhibitors suppress the tumor-forming ability of TNBC. To determine the effects of the signaling pathway inhibitors on the breast tumor-forming ability in vivo, HCC1806 cells pretreated with vehicle or inhibitors were injected into NOD/SCID mice. It was observed that all mice injected with vehicle-treated HCC1806 cells developed mammary tumors at 7 days following injection (Fig. 7A). In contrast, mice injected with inhibitor-treated HCC1806 cells exhibited a delay in tumor formation and a decrease in tumor incidence (Fig. 7A). At 21 days after injection, all the mice in the treatment groups exhibited a significant decreased tumor volume compared with the control group (Fig. 7B and C; $\mathrm{P}<0.05)$, suggesting that these inhibitors suppress the growth of BSBC-derived tumors in vivo.

\section{Discussion}

The present study aimed to determine if inhibitors of the Notch, Hedgehog, Wnt and JAK/STAT signaling pathways may be used as potential therapeutic agents targeting BCSCs in TNBC. It was demonstrated that the five signaling pathway inhibitors, DAPT, GDC-0449, salinomycin, ruxolitinib and stattic, individually suppressed the proliferation and promoted the apoptosis of HCC38 cells, a TNBC cell line with stem cell-like characteristics $\left(\mathrm{CD} 44^{+} / \mathrm{CD} 24^{\text {low/- }}\right.$ and $\left.\mathrm{ALDH}^{+}\right)$that exhibits the features of BCSCs. The invasion assay demonstrated that the five inhibitors significantly decreased HCC38 invasion compared with the control group, suggesting their suppressive effects on the breast cancer invasive capacity. In addition, these inhibitors blocked the BCSC mammosphere process by preventing mammosphere formation and promoting mammosphere disassembly, suggesting that these inhibitors may simultaneously inhibit the proliferation and differentiation of cancer stem cells. However, it was observed that GDC-0449 and ruxolitinib had no significant inhibitory effects on the mammosphere size. A possible explanation for this discrepancy is that the mammospheres were no longer sensitive to the present drug concentrations when they grew to a given size $(40 \mu \mathrm{m})$. The mammospheres $>40 \mu \mathrm{m}$ had limited drug contact with interior HCC38 cells due to their large size. Therefore, higher concentrations may be required to increase 
Downstream of the target genes over a DMSO control after treatment with the inhibitors
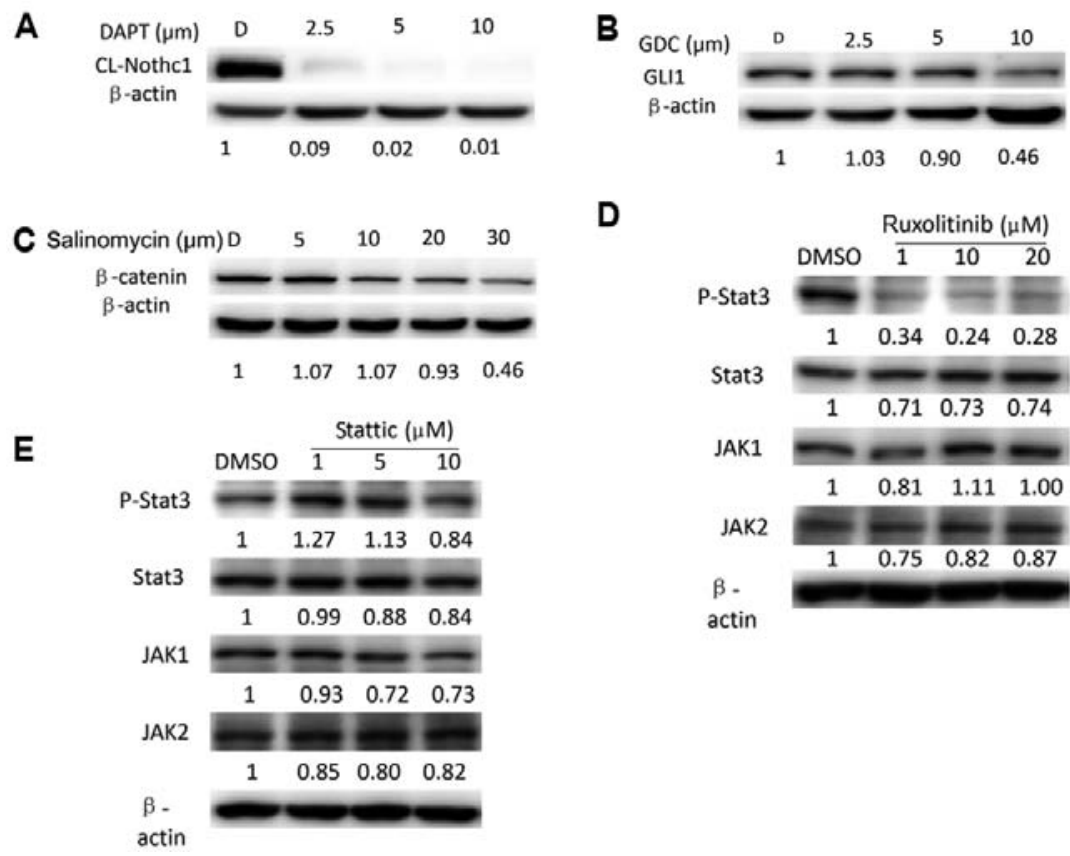

D

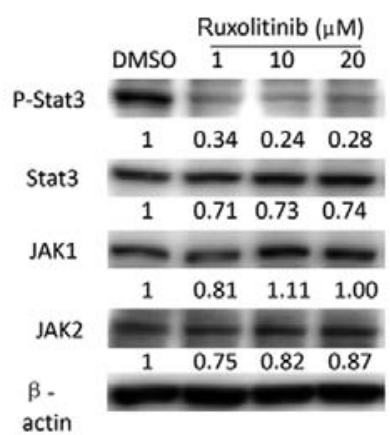

Figure 6. Signaling pathway inhibitors suppress expression or phosphorylation of downstream targets. Western blot analysis for the expression of (A) cl-Notch1, (B) GLI1, (C) $\beta$-catenin. Expression of p-STAT3, total STAT3, JAK1 and JAK2 in HCC38 cells treated with different concentrations of the (D) ruxolitinib and (E) stattic for $24 \mathrm{~h}$. All experiments were repeated at least three times. STAT3, signal transducer and activator of transcription; JAK, Janus kinase; p, phosphorylated; cl, cleaved; DMSO, dimethyl sulfoxide; GLI1, zinc finger protein GLI1.
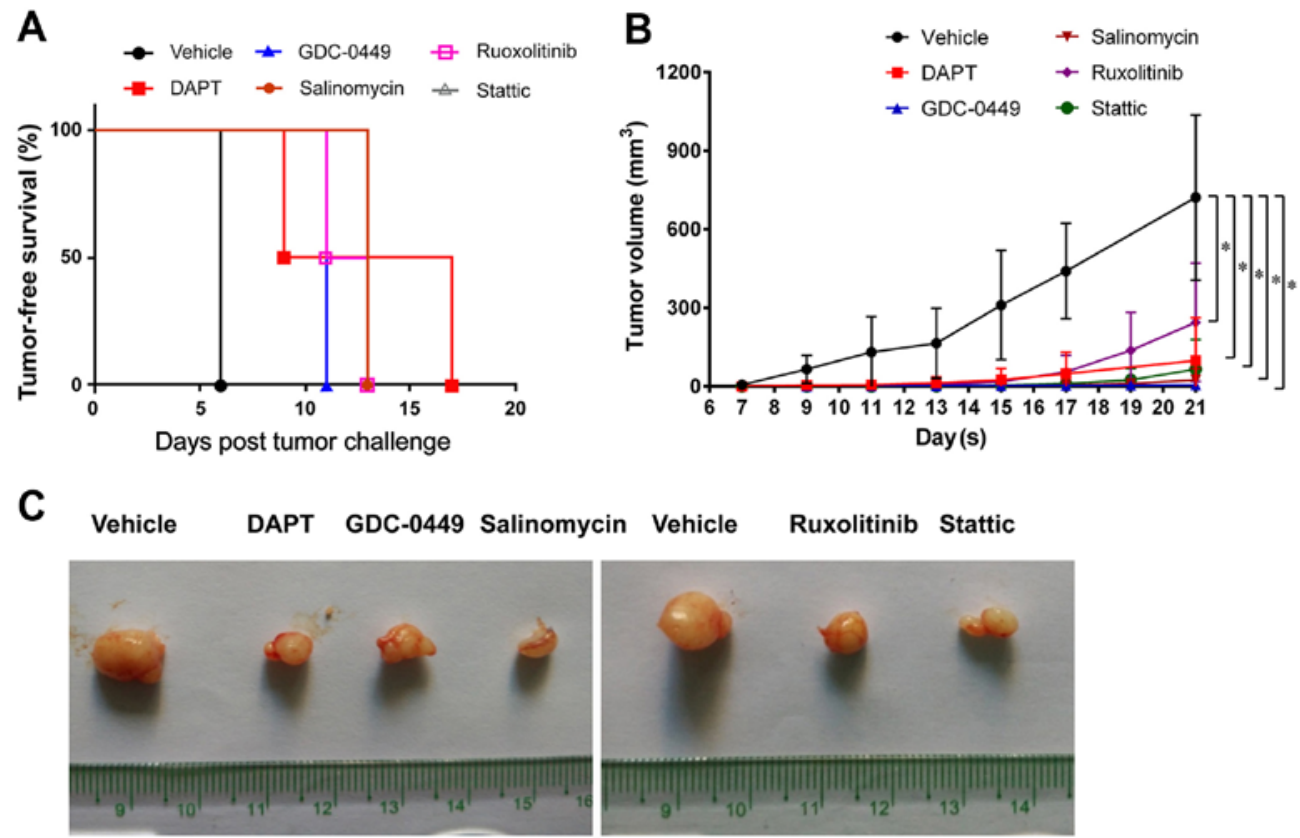

Figure 7. Signaling pathway inhibitors suppress the tumor-forming ability of HCC1806 cells. (A) Kaplan-Meier tumor-free survival curves are presented. $\mathrm{n}=3$ mice/group. Mice that received subcutaneous injections developed tumors following challenge with vehicle or signaling pathway inhibitor-treated HCC1806 cells. (B) Tumor growth curves are presented. $n=3$ mice/group. (C) Representative images of the tumors at 21 days after tumor inoculation. $n=3$. ${ }^{*} \mathrm{P}<0.05$ vs. vehicle. DAPT, $N$-[ $N$-(3,5-difluorophenacetyl)-L-alanyl]- $S$-phenylglycine $t$-butyl ester; GDC-0449, vismodegib.

the sensitivity of the mammospheres to these two inhibitors; further investigation in a future study is required. In the present study, only HCC38 cells $\left(100 \% \mathrm{ALDH}^{+}\right)$were used for the in vitro study as they are considered an ideal candidate cell line of BCSCs (23). To the best of the authors' knowledge, at present, no other cell line shares more characteristic features of BCSCs than HCC38. Therefore, data from HCC 38 cells are representative of an in vitro BCSC study.

DAPT is used as a $\gamma$-secretase inhibitor to block Notch signaling (24). The present study demonstrated that DAPT downregulated the expression of cl-Notch1, the activated form of the Notch1 receptor, $\leq 99 \%$ in HCC38 cells, demonstrating that 
DAPT prevents the final cleavage step of the Notch1 receptor by inactivating $\gamma$-secretase and subsequently decreasing the expression level of cl-Notch1 (25). As the Notch signaling pathway is dysregulated due to the overexpression of Notch receptors and their ligands in human breast cancer $(26,27)$, the expression of cl-Notch1 is a notable biomarker for therapeutic efficacy of drugs or agents in breast cancer $(28,29)$. Additionally, it was demonstrated that DAPT suppressed BCSC proliferation and tumor growth in vitro and in vivo. Therefore, DAPT may serve as a promising therapeutic agent in breast cancer by targeting the Notch signaling pathway in BCSCs.

GDC-0449 was used in the present study to target the Hedgehog signaling pathway, which is normally in a resting state; however, is activated in response to carcinogenic stimuli by hedgehog ligands binding to a transmembrane receptor called Patched (PTCH) (30). The hedgehog signaling pathway serves a significant role in cancer development and progression in various malignancies, including breast cancer (31-34). Following the hedgehog ligand-PTCH binding, smoothened (SMO) protein initiates the signaling cascade by activating GLI transcription factors, which in turn drive the expression of a variety of target genes that are associated with carcinogenesis $(35,36)$. In the present study, treatment with $40 \mu \mathrm{M}$ GDC-0449 led to $50 \%$ decrease in the GLI1 protein expression level in HCC38 cells, which is likely due to the direct inhibition of SMO by GDC-0449. Consistently, GDC-0449 inhibited BCSC proliferation, invasion and mammosphere formation, while inducing BCSC apoptosis. Based on the present in vivo data, it was hypothesized that SMO is undetectable in normal breast tissue however, is increased in breast cancer tissues. Consistently, SMO has been identified to be ectopically expressed in 70\% ductal carcinoma in situ and 30\% invasive breast cancer in an animal model (37), suggesting that inhibition of SMO is a valuable therapeutic strategy against BCSCs. Previously, GDC-0449 was approved by the US Food and Drug Administration for the treatment of advanced basalcell carcinoma (38-40), which may result in the future clinical application of GDC-0449 in breast cancer therapy.

Salinomycin was originally developed as a commercial antibiotic in veterinary medicine (41). A previous study demonstrated that salinomycin may additionally be used as an effective drug against breast cancer by targeting drug-resistant BCSCs (41). Previously, Lu et al (42) observed that salinomycin inhibits Wnt/ $\beta$-catenin signaling, a key signaling pathway supporting self-renewal of normal and malignant mammary stem cells (43). Enhanced Wnt signaling contributes to cell proliferation in the majority of breast cancer by downregulating the expression of secreted Frizzled-related protein 1, a negative Wnt pathway regulator (44). These results suggested that salinomycin is a promising anticancer drug by inhibiting $\mathrm{Wnt} / \beta$-catenin signaling. The present results demonstrated that salinomycin, by markedly decreasing the expression of $\beta$-catenin, significantly suppressed BCSC proliferation and mammosphere formation in vitro in addition to tumor formation in vivo.

Ruxolitinib (Jakafi) and stattic are inhibitors of the JAK/ STAT3 pathway, another important pathway in normal and cancer stem cells, which is considered a promising therapeutic target (45). JAKs phosphorylate STATs, thus subsequently activating the signaling pathway and various target genes (46). Ruxolitinib and stattic inhibit JAKs and
STATs, respectively $(47,48)$. In the present study, ruxolitinib markedly downregulated the expression of phospho-STAT3; however, appeared to have no marked effects on JAK1 and JAK2 expression. A possible explanation for this discrepancy is that the activities of JAK 1 and JAK2 are determined by their phosphorylation levels, not by their protein expression levels. However, stattic did not appear to markedly alter the expression of all four proteins. Phosphorylation levels of JAK1 and JAK2 require examination to further conform the role of stattic in suppressing breast cancer in future studies. Furthermore, further investigation is required to examine the expression pattern of SMO in the inhibitors-treated BCSCs, which may provide novel insight for the underlying mechanisms.

Although a number of previous studies demonstrated that these five signaling inhibitors exert inhibitory effects on TNBC in animal models and in clinical trials (49-53), in the present study, it was demonstrated that all five signaling inhibitors suppressed stemness of BCSCs in extensive aspects, including proliferation, invasion, apoptosis, self-renewal, mammosphere formation and tumorigenesis. In addition, the inhibition efficacy of these five inhibitors against TNBC was compared. The present in vitro and in vivo data demonstrated that these five signaling inhibitors, individually or in combination, may be applied clinically with high efficacy.

In conclusion, it was demonstrated that the signaling pathway inhibitors suppressed BCSC proliferation, invasion and mammosphere number, while inducing apoptosis. As these signaling pathway inhibitors, with the exception of stattic, have been applied clinically or in clinical trials for the intervention of disorders other than TNBC, including operable basal cell carcinoma, myelofibrosis and coccidial infection (54-60), they may provide novel therapeutic options for TNBC.

\section{Acknowledgements}

The authors would like to thank Dr Shibo Fu of the Transforming Medical College of First Hospital, Jilin University (Changchun, China), who revised the manuscript and conducted the western blot experiments.

\section{Funding}

The present study was financially supported by the Bethune Plan B (Jilin, China; grant no. 2012217), the National Natural Scientific Fund of China Grant (grant no. 30300336) and the Health Specific Programme of Jilin Province (grant no. 2018SCZWSZX-035).

\section{Availability of data and materials}

All data generated or analyzed during this study are included in this published article.

\section{Authors' contributions}

WL, HY and XL performed the examination. XL and LH prepared the figures. LH and NX conducted the statistical analyses. AS analyzed and interpreted the data, and was the principal contributor in writing the manuscript. All authors read and approved the final manuscript. 


\section{Ethics approval and consent to participate}

All the animal care details and procedures described in the present study were approved by the Ethics Committee of The First Hospital of Jilin University (Changchun, China). All animal experiments were performed in accordance with guidelines for proper conduct of animal experiments (Jilin University).

\section{Patient consent for publication}

Not applicable.

\section{Competing interests}

The authors declare that they have no competing interests.

\section{References}

1. Siegel RL, Miller KD and Jemal A: Cancer Statistics, 2017. CA Cancer J Clin 67: 7-30, 2017.

2. Bauer KR, Brown M, Cress RD, Parise CA and Caggiano V: Descriptive analysis of estrogen receptor (ER)-negative, progesterone receptor (PR)-negative, and HER2-negative invasive breast cancer, the so-called triple-negative phenotype: A population-based study from the California cancer Registry. Cancer 109: 1721-1728, 2007.

3. Dent R, Trudeau M, Pritchard KI, Hanna WM, Kahn HK, Sawka CA, Lickley LA, Rawlinson E, Sun P and Narod SA: Triple-negative breast cancer: Clinical features and patterns of recurrence. Clin Cancer Res 13: 4429-4434, 2007.

4. Atkinson RL, Yang WT, Rosen DG, Landis MD, Wong H, Lewis MT, Creighton CJ, Sexton KR, Hilsenbeck SG, Sahin AA, et al: Cancer stem cell markers are enriched in normal tissue adjacent to triple negative breast cancer and inversely correlated with DNA repair deficiency. Breast Cancer Res 15: R77, 2013.

5. Lehmann BD, Bauer JA, Chen X, Sanders ME, Chakravarthy AB, Shyr Y and Pietenpol JA: Identification of human triple-negative breast cancer subtypes and preclinical models for selection of targeted therapies. J Clin Invest 121: 2750-2767, 2011.

6. Burstein MD, Tsimelzon A, Poage GM, Covington KR, Contreras A, Fuqua SA, Savage MI, Osborne CK, Hilsenbeck SG, Chang JC, et al: Comprehensive genomic analysis identifies novel subtypes and targets of triple-negative breast cancer. Clin Cancer Res 21: 1688-1698, 2015.

7. Dalerba P, Cho RW and Clarke MF: Cancer stem cells: Models and concepts. Annu Rev Med 58: 267-284, 2007.

8. Geng SQ, Alexandrou AT and Li JJ: Breast cancer stem cells: Multiple capacities in tumor metastasis. Cancer Lett 349: 1-7, 2014.

9. Collina F, Di Bonito M, Li Bergolis V, De Laurentiis M, Vitagliano C, Cerrone M, Nuzzo F, Cantile M and Botti G: Prognostic value of cancer stem cells markers in triple-negative breast cancer. BioMed Res Int 2015: 158682, 2015.

10. Al-Hajj M, Wicha MS, Benito-Hernandez A, Morrison SJ and Clarke MF: Prospective identification of tumorigenic breast cancer cells. Proc Natl Acad Sci USA 100: 3983-3988, 2003.

11. Ginestier C, Hur MH, Charafe-Jauffret E, Monville F, Dutcher J, Brown M, Jacquemier J, Viens P, Kleer CG, Liu S, et al: ALDH1 is a marker of normal and malignant human mammary stem cells and a predictor of poor clinical outcome. Cell Stem Cell 1: 555-567, 2007

12. Resetkova E, Reis-Filho JS, Jain RK, Mehta R, Thorat MA, Nakshatri $\mathrm{H}$ and Badve S: Prognostic impact of ALDH1 in breast cancer: A story of stem cells and tumor microenvironment. Breast Cancer Res Treat 123: 97-108, 2010.

13. Charafe-Jauffret E, Ginestier C, Bertucci F, Cabaud O, Wicinski J, Finetti P, Josselin E, Adelaide J, Nguyen TT, Monville F, et al: ALDH1-positive cancer stem cells predict engraftment of primary breast tumors and are governed by a common stem cell program. Cancer Res 73: 7290-7300, 2013.

14. Alamgeer M, Ganju V, Kumar B, Fox J, Hart S, White M, Harris M, Stuckey J, Prodanovic Z, Schneider-Kolsky ME, et al: Changes in aldehyde dehydrogenase-1 expression during neoadjuvant chemotherapy predict outcome in locally advanced breast cancer. Breast Cancer Res 16: R44, 2014.
15. Marcato P, Dean CA, Liu RZ, Coyle KM, Bydoun M, Wallace M, Clements D, Turner C, Mathenge EG, Gujar SA, et al: Aldehyde dehydrogenase 1A3 influences breast cancer progression via differential retinoic acid signaling. Mol Oncol 9: 17-31, 2015.

16. Pires BR, DE Amorim ÍS, Souza LD, Rodrigues JA and Mencalha AL: Targeting cellular signaling pathways in breast cancer stem cells and its implication for cancer treatment. Anticancer Res 36: 5681-5691, 2016.

17. Takebe N, Miele L, Harris PJ, Jeong W, Bando H, Kahn M, Yang SX and Ivy SP: Targeting Notch, Hedgehog, and Wnt pathways in cancer stem cells: Clinical update. Nat Rev Clin Oncol 12: 445-464, 2015.

18. Frank NY, Schatton T and Frank MH: The therapeutic promise of the cancer stem cell concept. J Clin Invest 120: 41-50, 2010.

19. Naito S, von Eschenbach AC, Giavazzi R and Fidler IJ: Growth and metastasis of tumor cells isolated from a human renal cell carcinoma implanted into different organs of nude mice. Cancer Res 46: 4109-4115, 1986.

20. Krakhmal NV, Zavyalova MV, Denisov EV, Vtorushin SV and Perelmuter VM: Cancer invasion: Patterns and mechanisms. Acta Naturae 7: 17-28, 2015.

21. Shaw FL, Harrison H, Spence K, Ablett MP, Simões BM, Farnie G and Clarke RB: A detailed mammosphere assay protocol for the quantification of breast stem cell activity. J Mammary Gland Biol Neoplasia 17: 111-117, 2012.

22. Harrison H, Farnie G, Howell SJ, Rock RE, Stylianou S, Brennan KR, Bundred NJ and Clarke RB: Regulation of breast cancer stem cell activity by signaling through the Notch4 receptor. Cancer Res 70: 709-718,2010.

23. Londoño-Joshi AI, Oliver PG, Li Y, Lee CH, Forero-Torres A, LoBuglio AF and Buchsbaum DJ: Basal-like breast cancer stem cells are sensitive to anti-DR5 mediated cytotoxicity. Breast Cancer Res Treat 133: 437-445, 2012.

24. Jiang LY, Zhang XL, Du P and Zheng JH: $\gamma$-Secretase inhibitor, DAPT inhibits self-renewal and stemness maintenance of ovarian cancer stem-like cells in vitro. Chin J Cancer Res 23: 140-146, 2011.

25. Olsauskas-Kuprys R, Zlobin A and Osipo C: Gamma secretase inhibitors of Notch signaling. Onco Targets Ther 6: 943-955, 2013.

26. Imatani A and Callahan R: Identification of a novel NOTCH-4/ INT-3 RNA species encoding an activated gene product in certain human tumor cell lines. Oncogene 19: 223-231, 2000.

27. Stylianou S, Clarke RB and Brennan K: Aberrant activation of notch signaling in human breast cancer. Cancer Res 66: 1517-1525, 2006.

28. Stoeck A, Lejnine S, Truong A, Pan L, Wang H, Zang C, Yuan J, Ware C, MacLean J, Garrett-Engele PW, et al: Discovery of biomarkers predictive of GSI response in triple-negative breast cancer and adenoid cystic carcinoma. Cancer Discov 4: 1154-1167, 2014.

29. Zhong Y, Shen S, Zhou Y, Mao F, Lin Y, Guan J, Xu Y, Zhang S, Liu X and Sun Q: NOTCH1 is a poor prognostic factor for breast cancer and is associated with breast cancer stem cells. OncoTargets Ther 9: 6865-6871, 2016.

30. Gupta S, Takebe N and Lorusso P: Targeting the Hedgehog pathway in cancer. Ther Adv Med Oncol 2: 237-250, 2010.

31. Beachy PA, Hymowitz SG, Lazarus RA, Leahy DJ and Siebold C: Interactions between Hedgehog proteins and their binding partners come into view. Genes Dev 24: 2001-2012, 2010.

32. Varjosalo $M$ and Taipale J: Hedgehog: Functions and mechanisms. Genes Dev 22: 2454-2472, 2008.

33. Mullor JL, Sánchez P and Ruiz i Altaba A: Pathways and consequences: Hedgehog signaling in human disease. Trends Cell Biol 12: 562-569, 2002 .

34. Ng JMY and Curran T: The Hedgehog's tale: Developing strategies for targeting cancer. Nat Rev Cancer 11: 493-501, 2011.

35. Odoux C, Fohrer H, Hoppo T, Guzik L, Stolz DB, Lewis DW, Gollin SM, Gamblin TC, Geller DA and Lagasse E: A stochastic model for cancer stem cell origin in metastatic colon cancer. Cancer Res 68: 6932-6941, 2008.

36. Amakye D, Jagani Z and Dorsch M: Unraveling the therapeutic potential of the Hedgehog pathway in cancer. Nat Med 19: 1410-1422, 2013.

37. Moraes RC, Zhang X, Harrington N, Fung JY, Wu MF, Hilsenbeck SG, Allred DC and Lewis MT: Constitutive activation of smoothened (SMO) in mammary glands of transgenic mice leads to increased proliferation, altered differentiation and ductal dysplasia. Development 134: 1231-1242, 2007. 
38. Sandhiya S, Melvin G, Kumar SS and Dkhar SA: The dawn of hedgehog inhibitors: Vismodegib. J Pharmacol Pharmacother 4: 4-7, 2013.

39. Rudin CM, Hann CL, Laterra J, Yauch RL, Callahan CA, Fu L, Holcomb T, Stinson J, Gould SE, Coleman B, et al: Treatment of medulloblastoma with hedgehog pathway inhibitor GDC-0449. N Engl J Med 361: 1173-1178, 2009.

40. Von Hoff DD, LoRusso PM, Rudin CM, Reddy JC, Yauch RL, Tibes R, Weiss GJ, Borad MJ, Hann CL, Brahmer JR, et al: Inhibition of the hedgehog pathway in advanced basal-cell carcinoma. N Engl J Med 361: 1164-1172, 2009.

41. Gupta PB, Onder TT, Jiang G, Tao K, Kuperwasser C, Weinberg RA and Lander ES: Identification of selective inhibitors of cancer stem cells by high-throughput screening. Cell 138: 645-659, 2009.

42. Lu D, Choi MY, Yu J, Castro JE, Kipps TJ and Carson DA: Salinomycin inhibits Wnt signaling and selectively induces apoptosis in chronic lymphocytic leukemia cells. Proc Natl Acad Sci USA 108: 13253-13257, 2011.

43. Smalley MJ and Dale TC: Wnt signalling in mammalian development and cancer. Cancer Metastasis Rev 18: 215-230, 1999.

44. Schlange T, Matsuda Y, Lienhard S, Huber A and Hynes NE: Autocrine WNT signaling contributes to breast cancer cell proliferation via the canonical WNT pathway and EGFR transactivation. Breast Cancer Res 9: R63, 2007.

45. Hernandez-Vargas H, Ouzounova M, Le Calvez-Kelm F, Lambert MP, McKay-Chopin S, Tavtigian SV, Puisieux A Matar C and Herceg Z: Methylome analysis reveals Jak-STAT pathway deregulation in putative breast cancer stem cells. Epigenetics 6: 428-439, 2011.

46. Buchert M, Burns CJ and Ernst M: Targeting JAK kinase in solid tumors: Emerging opportunities and challenges. Oncogene 35: 939-951, 2016.

47. Schust J, Sperl B, Hollis A, Mayer TU and Berg T: Stattic: A small-molecule inhibitor of STAT3 activation and dimerization. Chem Biol 13: 1235-1242, 2006.

48. Tavallai M, Booth L, Roberts JL, Poklepovic A and Dent P: Rationally repurposing ruxolitinib (Jakafi $(\circledR)$ ) as a solid tumor therapeutic. Front Oncol 6: 142, 2016.

49. Aktas CC, Zeybek ND and Piskin AK: In vitro effects of phenytoin and DAPT on MDA-MB-231 breast cancer cells. Acta Biochim Biophys Sin (Shanghai) 47: 680-686, 2015.
50. Kai M, Kanaya N, Wu SV, Mendez C, Nguyen D, Luu T and Chen S: Targeting breast cancer stem cells in triple-negative breast cancer using a combination of LBH589 and salinomycin. Breast Cancer Res Treat 151: 281-294, 2015.

51. Stover DG, Gil Del Alcazar CR, Brock J, Guo H, Overmoyer B, Balko J, Xu Q, Bardia A, Tolaney SM, Gelman R, et al: Phase II study of ruxolitinib, a selective JAK1/2 inhibitor, in patients with metastatic triple-negative breast cancer. NPJ Breast Cancer 4: 10, 2018.

52. Rai G, Suman S, Mishra S and Shukla Y: Evaluation of growth inhibitory response of Resveratrol and Salinomycin combinations against triple negative breast cancer cells. Biomed Pharmacother 89: 1142-1151, 2017.

53. Habib JG and O'Shaughnessy JA: The hedgehog pathway in triple-negative breast cancer. Cancer Med 5: 2989-3006, 2016.

54. Robarge KD, Brunton SA, Castanedo GM, Cui Y, Dina MS, Goldsmith R, Gould SE, Guichert O, Gunzner JL, Halladay J, et al: GDC-0449-a potent inhibitor of the hedgehog pathway. Bioorg Med Chem Lett 19: 5576-5581, 2009.

55. Luistro L, He W, Smith M, Packman K, Vilenchik M, Carvajal D, Roberts J, Cai J, Berkofsky-Fessler W, Hilton H, et al: Preclinical profile of a potent gamma-secretase inhibitor targeting notch signaling with in vivo efficacy and pharmacodynamic properties. Cancer Res 69: 7672-7680, 2009.

56. Fan X, Khaki L, Zhu TS, Soules ME, Talsma CE, Gul N, Koh C, Zhang J, Li YM, Maciaczyk J, et al: NOTCH pathway blockade depletes CD133-positive glioblastoma cells and inhibits growth of tumor neurospheres and xenografts. Stem Cells 28: 5-16, 2010.

57. Antoszczak M and Huczyński A: Anticancer Activity of Polyether Ionophore-Salinomycin. Anticancer Agents Med Chem 15: 575-591, 2015.

58. Zhang Q, Zhang C, He J, Guo Q, Hu D, Yang X, Wang J, Kang Y, She R, Wang Z, et al: STAT3 inhibitor stattic enhances radiosensitivity in esophageal squamous cell carcinoma. Tumour Biol 36 : 2135-2142, 2015.

59. Plosker GL: Ruxolitinib: A review of its use in patients with myelofibrosis. Drugs 75: 297-308, 2015

60. Vannucchi AM, Kiladjian JJ, Griesshammer M, Masszi T, Durrant S, Passamonti F, Harrison CN, Pane F, Zachee P, Mesa R, et al: Ruxolitinib versus standard therapy for the treatment of polycythemia vera. N Engl J Med 372: 426-435, 2015. 